\title{
Rubinstein-Taybi Syndrome: A case report
}

\author{
by Taren Cardona, BS ${ }^{1}$, Al Kline, DPM $^{2} \square$
}

\section{The Foot \& Ankle Journal 1 (7): 3}

Rubinstein-Taybi Syndrome (RSTS) is a rare genetic disorder. Individuals are characterized by broad halluces and thumbs, hyper-extensible joints and other classic features. The broad hallux often leads to complications such as ingrown toe nails. The syndrome is extremely rare and this appears to be the first reported case in the podiatric literature.

Key words: Rubinstein-Taybi Syndrome, RSTS, Onychocryptosis

Accepted: May 2008

Published: July 2008

This is an Open Access article distributed under the terms of the Creative Commons Attribution License. It permits unrestricted use, distribution, and reproduction in any medium, provided the original work is properly cited. @The Foot \& Ankle Journal (www.faoj.org)

$\mathbf{R}_{\mathrm{u}}$ ubinstein-Taybi Syndrome (RSTS) was first described in 1957 as a single case report, and then in 1963 Rubinstein and Taybi described a syndrome of broad fingers and great toes, facial abnormalities and mental retardation as observed in seven children. ${ }^{7}$ Clinical characteristics of these individuals include short stature, beaked nose, anti-mongoloid slant of eyes, heavy/high arched eyebrows, microcephaly, broad thumbs and hallux which are often angulated, hyper-extensive joints, small tilted pelvis, hypertrichosis, and undescended testes. ${ }^{2}$

Address correspondence to: Al Kline, DPM

3130 South Alameda, Corpus Christi, Texas 78404.

${ }^{1}$ Submitted during clinical clerkship in May 2008, Corpus Christi, Texas 78404. Fourth year podiatry student, Barry University School of Podiatric Medicine.

2 Adjunct Clinical Faculty, Barry University School of Podiatric Medicine. Private practice, Chief of Podiatry, Doctors Regional Medical Center. Corpus Christi, Texas, 78411.
Current literature reports that $100 \%$ of all RSTS patients present with broad halluces. The condition is extremely rare $(1: 300,000$ up to $1: 1,000,000){ }^{2} \quad$ The podiatric and orthopedic community should be aware of the syndrome and its associated complications. The purpose of this report is to provide information on RSTS and the associated complications. In this paper we report a case encountered on referral for ingrown hallux nail.

\section{Case Report}

A 12 year old male presents to the office setting with a painful ingrown toe nail with a broad hallux and nail plate. The patient's medical history includes Rubinstein-Taybi Syndrome (RSTS), a recent surgery on bilateral polluces, previous foot surgery and a heart condition at birth. The patient appeared small for his stated age and had striking facial features. (Figs. 1) He was very pleasant on examination and mentally retarded. 


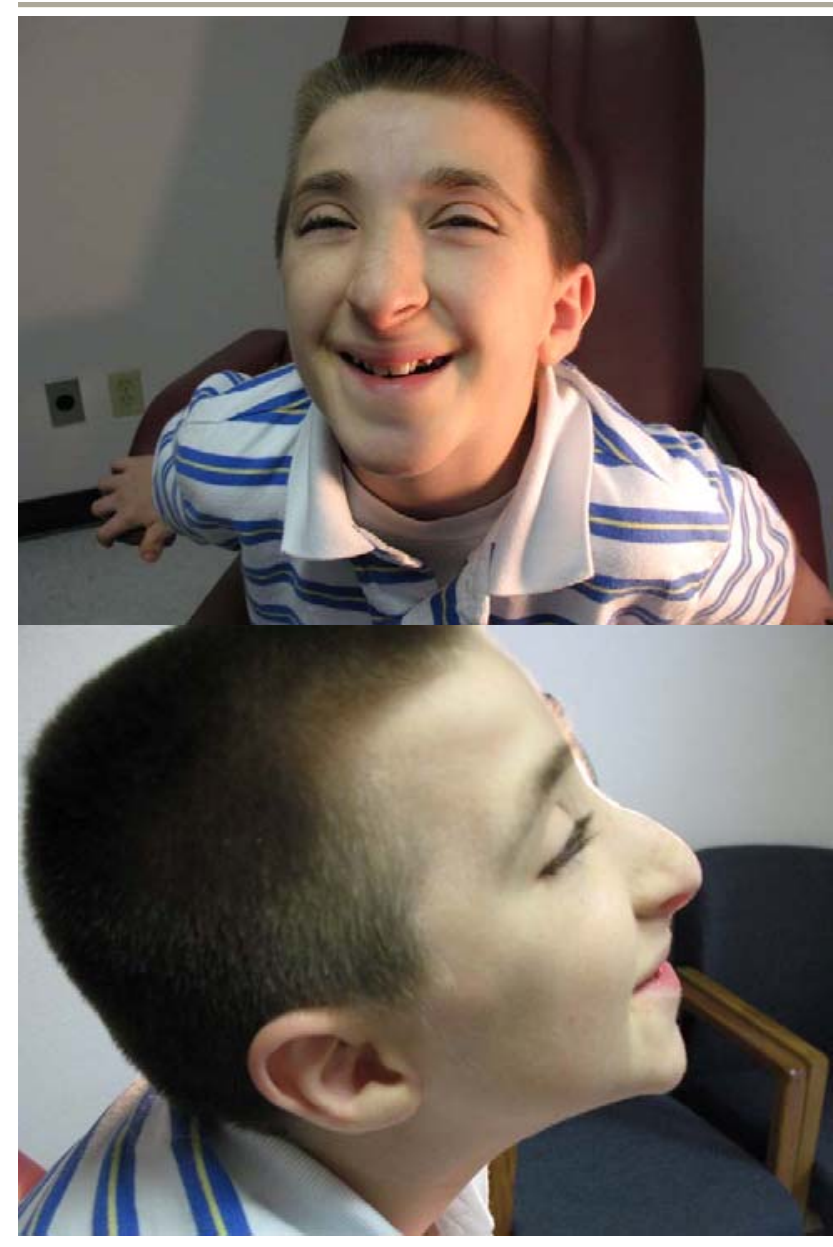

Figures 1 The facial features of Rubinstein-Taybi Syndrome. These include anti-mongoloid slant of eyes, heavy eye brows, low set ears and beaked nose.

Clinically, the hallux was broad bilaterally and a skin cleft was noted along the plantar first interspace. (Fig. 2) The patient's hallux nail was incurvated with mild hypertrophy to the ungula labia of the nail folds. (Fig. 3) There is positive pain on palpation of the area as evident from his withdraw response. Hyperextensible joints were noted. The patient's thumbs were broad with recently corrected radial angulation. (Figs. 4)

Since the hallux nail was painful, we elected to perform a modified Winograd procedure as an outpatient procedure in a surgical center. Anesthesia administered nitrous oxide via mask and local anesthetic with tourniquet was utilized.

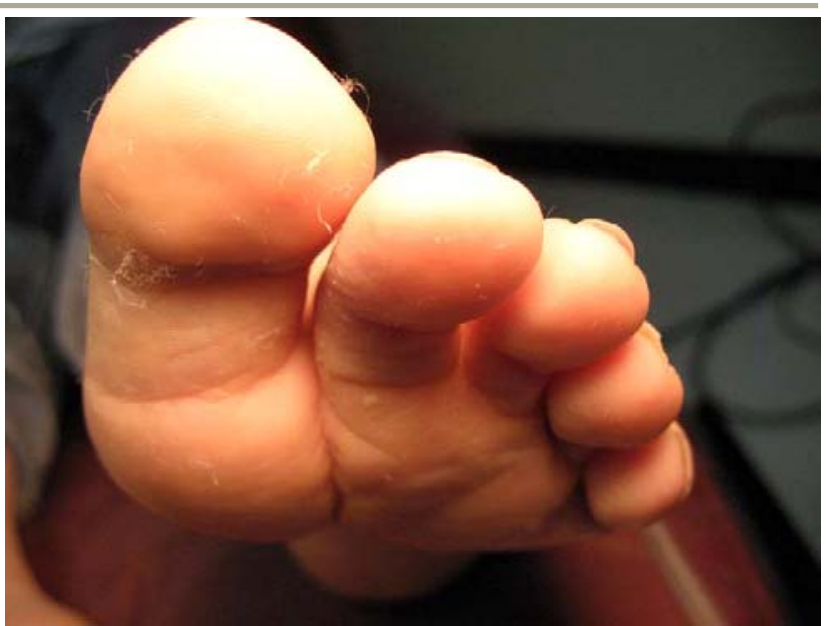

Figure 2 There is a plantar cleft to the plantar first interspace, hyper-extensible joint and broad hallux.

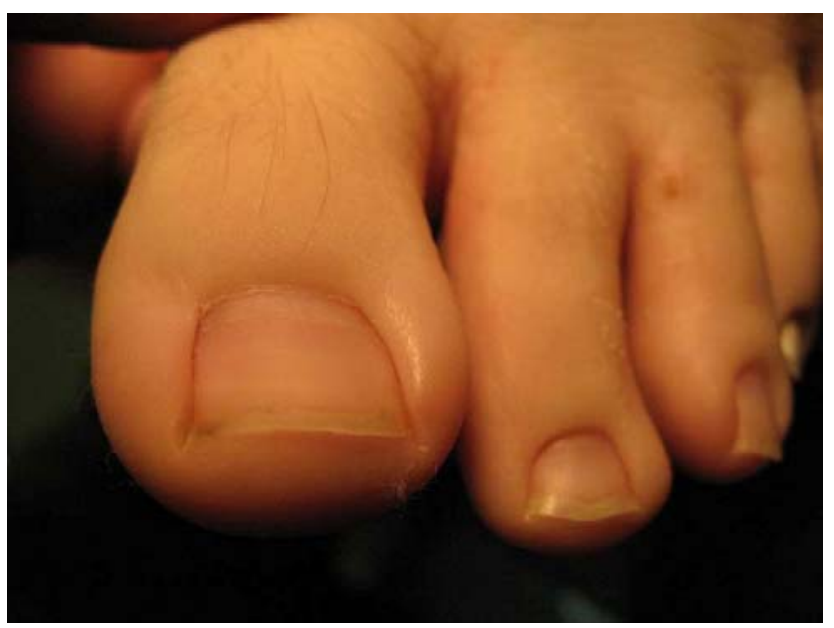

Figure 3 The hallux nail plate is broad with inflammation and pain to the nail borders and ungula nail folds.

Patient tolerated the procedure well with no complication.

\section{Discussion}

Although this was a simple case of onychocryptosis, we found this presenting case worthy of documentation and literature review. It appears there is very little documented evidence of this syndrome in the podiatric and orthopaedic literature. 


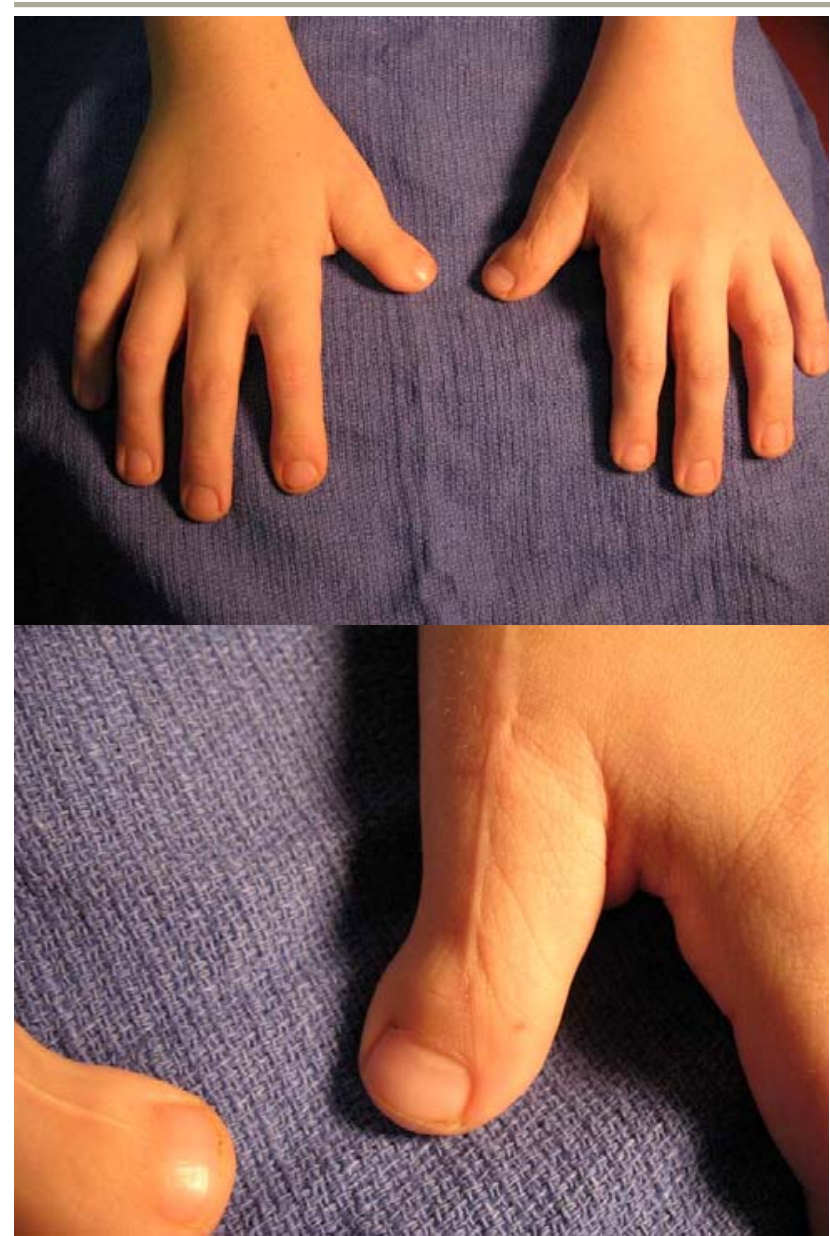

Figures 4 The thumbs have been corrected from ulnar deviation. The broadness of the thumb is still evident.

RSTS occurs when a mutation of the CREBbinding protein (CREBBP) causes a genetic defect. Although several molecular and genetic investigations have been undertaken, the syndrome has not been definitively characterized by a single deletion or translocation. One of the more common findings is a mutation of the EP300 gene and that a microdeletion is most likely the problem. Petrij, et al., reported all patients with RSTS studied demonstrated a deletion at 16p13.3 with is the region coding for CREBBP. ${ }^{5}$ CREBBP is a transcription coactivator and functions as a potent histone acetyltransferase, both of which are essential to normal development. ${ }^{6}$ Petriji, et al., proposed that the loss of one functional allele for the CREBBP is responsible for the propensity of RSTS patients to form neoplams and keloids.
In animal models, the mice with truncated $\mathrm{Crb}$ protein demonstrated clinical features of RSTS observed in humans including growth retardation, retarded osseous maturation, hypoplastic maxilla with narrow palate, cardiac and skeletal abnormalities. $^{4}$

Clinically there is a variety of symptoms observed in this syndrome. All patients $(100 \%)$ are observed to have a broad hallux and hypoplastic maxilla with narrow palate. Commonly observed features include: prominent beaked nose $(90 \%)$, antimongoloid palpebral fissures (88\%), lowset/malformed ears (84\%), strabismus (69\%), broad thumbs with radial angulation (87\%), broad fingers $(87 \%)$, mental retardation with IQ of less than 50 found (>50\%), speech difficulties (90\%), hypotonia $(67 \%)$, hirsutism $(75 \%)$, capillary nevus of the forehead or the nape $(>50 \%)$, and cryptorchidism $\left(78 \%\right.$ of males). ${ }^{3}$

Also described are large anterior fontanelle (41\%), microcephaly (35\%), Small mouth, persistent fetal finger pads (31\%), duplicated longitudinal bracketed epiphysis (kissing delta phalanx), syndactyly, polydactyly, ulnar deviation of the thumb, congenital or juvenile glaucoma, ptosis, growth retardation, echolalia, retarded osseous maturation (49\%), vertebral and sternal abnormalities, patellar dislocation, patellofemoral instability, fourth cuneiform bones, joint hyper mobility, keloid formation (4.87\%), cardiac anomalies (32.6\%), and ECG abnormalities $(30 \%) .^{3}$

Our patient presented with the characteristic broad hallux bilaterally, small jaw and beaked nose, anti Mongoloid eye slant, low set ears, surgically corrected thumbs, short and stubby fingers, mental retardation, echolalia and speech difficulty, hyperextensible joints, and keloid formation. The finding of chronic ingrown nails is most likely a consequence of a broad hallux. Baran described a condition of "Congenital malalignment of the great toenails" and proposed that a nail plate which is not parallel with the distal phalanx is the cause of recurrent ingrown nails. ${ }^{1}$ 
The hypermobility of the first metatarsophalangeal joint with broad hallux may explain the unusual skin cleft to the plantar first interspace of the foot.

Another important aspect of RSTS is the proclivity of patients to be sensitive to succinylcholine. Cardiac arrhythmia can develop with administration, so the clinician must be aware of the condition and possible adverse reactions. It is advised that patients be treated with sedation and local anesthetic when applicable rather than general anesthesia as intubation may necessitate muscle cell depolarization for insertion. Additionally these patients are at risk for aspiration during anesthesia due to laryngeal wall collapsibility, abnormal pulmonary lobulation, congenital tracheal stenosis, excess mucous secretion and gastro esophageal reflux all of which are common. ${ }^{3}$

In conclusion, RSTS is a rare genetic condition that invariably involves the lower extremity-in particular the halluces. We present this case report to inform the podiatric community of this condition and document a rare syndrome.

\section{References}

1. Baran R, Bureau H, Sayag J. Congenital malalignment of the big toenail. Clin Exp Dermatol. 4:359-360, 1979.

2. Baxter, Garry and Lorrie. Rubinstein-Taybi Parent Group. First Printing, April 90 Second Printing - Updated February 92 Third Printing, [Online].

3.Mijuskovic, Z. Rubinstein-Taybi Syndrome Last Updated: Sep 20, 2006. e-medicine.Author: Zeljko P Mijuskovic, MD, Coauthor(s): Djordjije Karadaglic, MD, DSc, Ljubomir Stojanov, MD, PhD, [Online].

4. Oike, Y.; Hata, A.; Mamiya, T.; Kaname, T.; Noda, Y.; Suzuki, M.; Yasue, H.; Nabeshima, T.; Araki, K.;

Yamamura, K. : Truncated CBP protein leads to classical Rubinstein-Taybi syndrome phenotypes in mice: implications for a dominant-negative mechanism. Hum. Molec. Genet. 8: 387-396, 1999.

5. Petrij, F.; Giles, R. H.; Dauwerse, H. G.; Saris, J. J.; Hennekam, R. C. M.; Masuno, M.; Tommerup, N.; van Ommen, G.-J. B.; Goodman, R. H.; Peters, D. J. M.; Breuning, M. H. : Rubinstein-Taybi syndrome caused by mutations in the transcriptional co-activator CBP. Nature 376: 348-351, 1995. PubMed ID : 7630403.

6. Roelfsema, J. H.; White, S. J.; Ariyurek, Y.; Bartholdi, D.; Niedrist, D.; Papadia, F.; Bacino, C. A.; den Dunnen, J. T.; van Ommen, G.-J. B.; Breuning, M. H.; Hennekam, R. C.; Peters, D. J. M. : Genetic heterogeneity in Rubinstein-Taybi syndrome: mutations in both the CBP and EP300 genes cause disease. Am. J. Hum. Genet. 76: 572-580, 2005.

7. Rubinstein, J. H.; Taybi, H. : Broad thumbs and toes and facial abnormalities. Am. J. Dis. Child. 105: 588-608, 1963. 